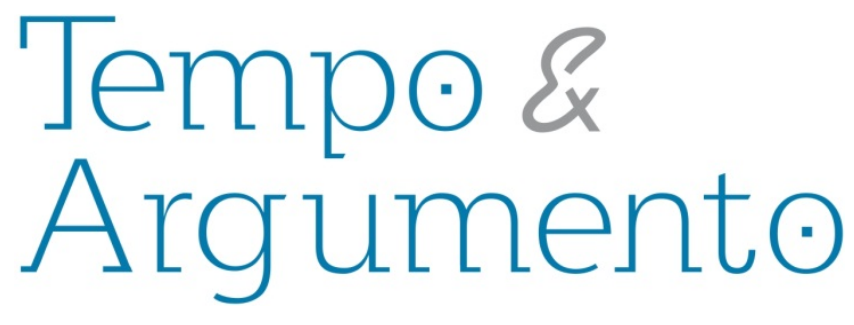

\title{
Convenção sobre os Direitos da Criança: em debate o labor infantojuvenil (1978 - 1989)
}

\section{Resumo}

Este artigo tem por objetivo descrever e analisar como se processou o debate acerca das relações de trabalho no campo da infância, adolescência e juventude durante a construção da Convenção sobre os Direitos da Criança pelos países membros da Organização das Nações Unidas e Organizações Não Governamentais entre 1978 e 1989. Buscase, também, apresentar informações sobre a presença do discurso jurídico desta normativa internacional na legislação brasileira para as crianças, adolescentes e jovens instituída no Brasil no ano de 1990.

Palavras-chave: História; Infância; Juventude; Direitos; Relações de Trabalho.

\author{
Silvia Maria Fávero Arend \\ Doutora em História pela Universidade \\ Federal do Rio Grande do Sul. Pós- \\ doutorado pela Fondation Nationale des \\ Sciences Politiques (Sciences Po - Paris). \\ Professora titular da Universidade do Estado \\ de Santa Catarina. \\ Brasil \\ smfarend@gmail.com
}

\section{Para citar este artigo:}

AREND, Silvia Maria Fávero. Convenção sobre os Direitos da Criança: em debate o labor infantojuvenil (1978 - 1989). Revista Tempo e Argumento, Florianópolis, v. 7, n.14, p. 29 - 47.

jan./abr. 2015.

DOI: $10.5965 / 2175180307142015029$

http://dx.doi.org/10.5965/2175180307142015029 


\title{
United Nations Convention on the Rights of the Child: child labor in debate (1978- 1989)
}

\begin{abstract}
This article aims to describe and analyze how processed the debate on work relations for children during the construction of the United Nations Convention on the Rights of the Child by United Nations members and Non-Governmental Organizations between the years of 1978 and 1989. The aim is to also provide information on the presence of legal discourse of this international instrument in the Brazilian legislation for children, instituted in the country in 1990.
\end{abstract}

Keywords: History; Childhood; Youth; Rights; Labor relations.

\section{Introdução}

Apesar de uma parcela significativa da sociedade não reconhecê-las, nos últimos trinta anos no Brasil', ocorreram mudanças em relação à infância, especialmente entre as camadas sociais mais pobres e em situação de precariedade. Neste período, este segmento populacional deixou de ser percebido apenas como um problema social para, aos poucos, constituir-se de sujeitos portadores de direitos. Este movimento, cujo expoente foi a legislação instituída em 1990, denominada Estatuto da Criança e do Adolescente, teve como protagonistas um conjunto de atores sociais, a saber: as famílias pobres, os operadores do Direito no Brasil, o corpo técnico e burocrático que formulava

\footnotetext{
${ }^{1}$ Neste artigo utiliza-se o vocábulo infância tendo em vista a população feminina e masculina que possuí entre zero e 21 anos de idade.
} 
as políticas sociais e o que atuava nas instituições de abrigo e/ou de internação, os militantes dos movimentos sociais (Pastoral do Menor, Pastoral da Criança, Movimento de Meninos e Meninas de Rua, etc.) e os representantes dos organismos internacionais. ${ }^{2}$

Neste artigo, analisa-se como se deu a construção do Artigo 32 da Convenção Universal sobre os Direitos da Criança, cuja temática é a exploração econômica e o labor infantojuvenil. ${ }^{3}$ O documento, produzido pela Organização Não Governamental Save the Children, denominado "Legislative History of the Convention on the Rights of the Child", subsidiará este estudo. Este documento, composto de dois volumes, descreve os debates ocorridos entre 1978 e 1989, entre os corpos diplomáticos das diferentes nações que compõem a Organização das Nações Unidas (ONU) e organizações não governamentais sobre as temáticas presentes na Convenção Universal sobre os Direitos da Criança. Buscar-se-á, também, verificar como os “ecos" das formulações presentes na referida normativa internacional repercutiram na legislação brasileira instituída em 1990. ${ }^{4}$

\section{Da Convenção sobre os Direitos da Criança}

Durante a década de 1980, a Organização das Nações Unidas promoveu um longo debate entre seus estados membros e outras entidades políticas e econômicas com objetivo de produzir um documento pautado no ideário dos Direitos Humanos para a população infantojuvenil (OESTREICH, 1998). Aquele organismo havia sido fundado, em 1945, na tentativa de criar uma entidade internacional global promotora do diálogo, visto que a sua antecessora, a Liga das Nações, demonstrou ineficácia ao não ter conseguido impedir a eclosão de uma nova guerra mundial em 1939. A formulação da Declaração Universal dos Direitos Humanos, em 1948, é considerada como uma das mais importantes realizações da referida instituição internacional. O caráter universal da declaração seria reforçado por sua aprovação sem reservas ou votos contrários entre os países-membros.

\footnotetext{
${ }^{2}$ BRASIL. Lei número 8.069, de 13 de julho de 1990.

${ }^{3}$ ORGANIZAÇÃO DAS NAÇÕES UNIDAS. Convenção sobre os Direitos da Criança, de 20 de novembro de 1989.

${ }^{4}$ Este artigo é resultado de pesquisa intitulada "Infância, lei e cidadania (Brasil, 1980-1990)" realizada durante estágio pós-doutoral efetuado na Fondation Nationale des Sciences Politique (Science Po) Paris/França. A investigação foi financiada pela Coordenação de Aperfeiçoamento de Pessoal de Nível Superior (CAPES)/Ministério da Educação/Brasil.
} 
De acordo com Flávia Piovesan, a Declaração Universal dos Direitos Humanos articula o discurso liberal e o discurso social da cidadania, somando o valor da liberdade ao valor da igualdade (PIOVESAN, 2013).

Em relação ao universo infantojuvenil, duas normativas de caráter internacional já haviam sido produzidas no século XX. A primeira fora elaborada em 1923 por uma organização não governamental chamada International Union for Child Welfare. Boa parte dos princípios desta normativa, denominada Declaração de Genebra, adotada pela Liga das Nações em 1924, deram origem àqueles presentes em sua sucessora, a Declaração dos Direitos da Criança, elaborada em 1959 pela Organização das Nações Unidas, embora com algumas mudanças significativas. Eis o que afirma Gustavo Ferraz de Campos Monaco sobre este documento:

O ponto principal dessa declaração (Resolução n. 1.386), relativamente a sua antecessora na proteção à infância, é a mudança de paradigma que instala, muito em função da consolidação da Declaração de 1948 que universaliza a proteção dos direitos humanos, uma vez que agora a criança passa a ser vista como sujeito de direitos e não mais como mero receptor passivo das ações realizadas em seu favor, dando-se início à aplicação de um pricípio que trinta anos depois seria inserto na convenção subsequente, que é o princípio do melhor interesse para a criança (MONACO, 2005, p. 128).

A Convenção sobre os Direitos da Criança, elaborada com a participação dos representantes diplomáticos do Brasil, foi aprovada em 1989. ${ }^{5}$ Esta normativa internacional começou a ser gestada, em 1978, a partir de um texto inicial apresentado pelos representantes do governo da Polônia à Organização das Nações Unidas. Neste texto incial, estavam expressos os preceitos dos Direitos Humanos aplicados ao universo infantojuvenil. Ao longo de 10 anos, representantes diplomáticos dos países membros da Organização das Nações Unidas e de Organizações Não Governamentais debateram os temas apresentados no texto inicial, bem como outras questões complementares. Este debate, conforme mencionado anteriormente, foi compilado no documento organizado

\footnotetext{
5 ORGANIZAÇÃO DAS NAÇÕES UNIDAS. Convenção sobre os Direitos da Criança, de 20 de novembro de 1989.
} 
pela Organização Não Governamental Save the Children, subsidiando a presente investigação. ${ }^{6}$

Nesta normativa internacional encontramos expressos os direitos humanos de alcance homogêneo, ou seja, que são preconizados para a população em geral independente da faixa etária e aqueles de alcance heterogêneo, que são específicos para os considerados menores de idade. Os princípios jurídicos dos direitos homogêneos reafirmados durante a infância são os seguintes: a igualdade, a compreensão, o desenvolvimento, a liberdade, a dignidade e a integridade física, mental e moral. Para Gustavo Ferraz de Campos Monaco, a garantia destes direitos para os infantes oportunizará que estes, ao ingressarem na fase adulta, alcancem a plena cidadania (MONACO, 2005, p. 148).

Entre os direitos de alcance homogêneos, destacam-se os exercitáveis durante a fase da vida denominada de infância, ou seja, o direito à alimentação, à educação, à saúde, à nacionalidade e a um nome e patronímico. A não garantia destes direitos homogêneos, segundo a perspectiva dos Direitos Humanos, pode acarretar sérios problemas na vida futura de uma determinada pessoa, seja em nível biológico, sociocultural ou ainda no campo dos direitos políticos.

O direito à convivência familiar, o direito a não trabalhar, o direito de proteção e socorro em momentos de dificuldades e necessidades extremas e os direitos das crianças consideradas deficientes são os denominados direitos de alcance heterogêneos. A introdução/implementação deste conjunto de direitos, pautado no ideário dos Direitos Humanos, possivelmente provoca modificação de práticas e valores levados a cabo há longa data por diversos atores sociais em diferentes sociedades, tais como o Estado, as famílias, as intituções de acolhimento pública e privadas, entre outros. Dentre os direitos de alcance heterogêneos, o direito a não trabalhar está associado a uma perspetiva de socialização das crianças, adolescentes e jovens a partir de outra ótica, a da escola. A introdução deste direito por muitos considerado radical, implica em mudanças significativas em práticas sociais vigentes, como demonstrado a seguir.

\footnotetext{
${ }^{6}$ Office of the United Nations High Commissioner for Human Rights. Legislative History of the Convention on the Rights of the Child, Save the Children, 2007.
} 


\section{Em cena debates acerca do labor infantojuvenil}

Observou-se que dentre os direitos de caráter heterôgeneo, as questões relativas ao labor de crianças, adolescentes e jovens suscitaram debates no processo de construção da Convenção sobre os Direitos da Criança. Cabe abordar estas discussões ocorridas durante 10 anos, ou seja, entre 1978 e 1989. No documento produzido pela Save the Children não há registro de pareceres emitidos pelos representates diplomáticos do Brasil sobre o referido tema, diferente de outros momentos de formulação da normativa, tais como a construção do Artigo 20, que trata da "Convivência Familiar", em que o corpo diplomático do Brasil se manifestou de forma efetiva no processo de redação da norma de Direito internacional.

Estes debates acerca do labor infantojuvenil ocorreram no processo de formulação do Artigo 32, da referida legislação, que possui a seguinte redação final que foi votada em 20 de novembro de 1989, na Assembleia Geral das Nações Unidas:

1. States Parties recognize the right of the child to be protected from economic exploitation and from performing any work that is likely to be hazardous or to interfere with the child's education, or to be harmful to the child's health or physical, mental, spiritual, moral or social development.

2. States Parties shall take legislative, administrative, social and educational measures to ensure the implementation of the present article. To this end, and having regard to the relevant provisions of other international instruments, States Parties shall in particular:

(a) Provide for a minimum age or minimum ages for admissions to employment;

(b) Provide for appropriate regulation of the hours and conditions of employment;

(c) Provide for appropriate penalties or other sanctions to ensure the effective enforcement of the present article (Office of the United Nations High Commissioner for Human Rights. Legislative History of the Convention on the Rights of the Child, Save the Children, 2007, p. 693). ${ }^{7}$

\footnotetext{
1. Os Estados Partes reconhecem à criança o direito de ser protegida contra a exploração econômica ou a sujeição a trabalhos perigosos ou capazes de comprometer a sua educação, prejudicar a sua saúde ou o seu desenvolvimento físico, mental, espiritual, moral ou social.

2. Os Estados Partes tomam medidas legislativas, administrativas, sociais e educativas para assegurar a aplicação deste artigo. Para esse efeito, e tendo em conta as disposições relevantes de outros instrumentos jurídicos internacionais, os Estados Partes devem, nomeadamente:
(a) Fixar uma idade mínima ou idades mínimas para a admissão a um emprego;
(b) Adotar regulamentos próprios relativos à duração e às condições de trabalho; 
A primeira redação que deu origem ao Artigo 32, apresentada em 1978, pelos representantes do governo da Polônia, era a seguinte:

1.The child shall be protected against all forms of neglect, cruelty and exploitation. He shall not be the subject of traffic, in any form.

2. The child shall not be admitted to employment before an appropriate minimum age; he shall in no case be caused or permitted to engage in any occupation or employment which would prejudice his health or education, or interfere with his physical, mental or moral development (Office of the United Nations High Commissioner for Human Rights. Legislative History of the Convention on the Rights of the Child, Save the Children, 2007, p. 693). ${ }^{8}$

Verificou-se que na redação inicial da normativa internacional apresentada pelo governo da Polônia, o parágrafo primeiro contemplava questões relativas ao tráfico de infantes que possivelmente atuariam no mundo do trabalho. Durante os debates sobre o labor infantojuvenil, esta temática não foi mais mencionada por nenhum dos países ou entidades não governamentais. Na redação final da normativa internacional, o Artigo 35 refere-se ao tráfico de pessoas. Outra questão importante de mencionar refere-se à localização do tema labor infantojuvenil na normativa. Na proposição inicial, a questão era tratada no Artigo IX. Posteriormente, durante os debates ocorridos durante os 10 anos, a temática foi tratada no Artigo 18. Na redação final do documento internacional, o tema foi apresentado no Artigo 32.

Entre a redação inicial e a redação final do Artigo 32, constatamos uma preocupação dos legisladores em regulamentar o labor infantojuvenil em relação a três questões. A primeira diz respeito à idade em que o infante pode ingressar no mercado de trabalho. De maneira geral, os corpos diplomáticos de vários países e instituições não governamentais sugeriram que meninos e meninas pudessem começar a trabalhar quando atigissem a idade de 14 anos. Somente a Organização Internacional do Trabalho — International Labour Organization (ILO) —, como demonstrar-se-á posteriormente,

(c) Prever penas ou outras sanções adequadas para assegurar uma efetiva aplicação deste artigo.

8 1. A criança será protegida contra toda forma de negligência, exploração ou crueldade. Ela não será sujeita ao tráfico de crianças, independente do seu fim ou forma.

2. A criança não será admitida a um emprego antes da idade mínima apropriada; ela não terá permissão de se engajar em quaisquer trabalhos perigosos ou capazes de comprometer sua educação, prejudicar sua saúde ou o seu desenvolvimento físico, mental, espiritual, moral ou social. 

deste processo.

A outra questão refere-se à quantidade de horas de trabalho, bem como os espaços/estabelecimentos em que as crianças, adolescentes e jovens poderiam trabalhar. Para os formuladores da legislação internacional, cada país necessitava regulamentar esta duas questões consideradas de vital importância no decorrer dos debates. O corpo diplomático da Nova Zelândia, visando demonstrar em quais setores da economia os menores de idade, de ambos os sexos, não mais trabalhavam em seu país, descreveu como se processou a regulamentação do labor infantojuvenil durante o século XX naquela sociedade. Em 1908, os meninos menores de 14 anos e as meninas menores de 16 anos foram interditados de pedir esmolas e vender bebidas alcoólicas nas ruas de cidades e vilarejos. Mais tarde, em 1925, os menores de 14 anos foram proibidos de trabalhar nas minas de carvão e, em 1939, os que tinham menos de 18 anos não poderiam atuar no setor petrolífero. A partir de 1946, as pessoas que tinham menos de 15 não podiam mais ingressar nas fábricas como operários e operárias. Na década de 1950, um conjunto de leis passou a não mais permitir que os jovens que tivessem menos de 15 anos de idade operassem máquinas de grande porte. Nos anos de 1960, foram regulamentadas atividades do setor comercial e do setor agrícola. Os legisladores neozelandezes enfatizaram que naquele momento histórico não havia mais crianças e jovens com idade inferior a 16 anos no mercado de trabalho do país. Os diplomatas afirmaram que até chegar a este cenário considerado “ideal”, o Estado neozelandês havia enfrentado muitos obstáculos, especialmente em relação ao setor agrícola, que utilizava mão-de-obra familiar. De forma concomitante à interdição das referidas atividades laborais, a educação escolar tornou-se obrigatória para todos os meninos e meninas da Nova Zelândia. ${ }^{9}$

A partir de proposição feita pelo corpo diplomático do Reino Unido, foi introduzida na Convenção sobre os Direitos da Criança a necessidade de estabelecer

\footnotetext{
${ }^{9}$ Office of the United Nations High Commissioner for Human Rights. Legislative History of the Convention on the Rights of the Child, Save the Children, 2007, p. 694-696.
} 
sanções para as pessoas/famílias/empresas que não cuprissem o que estava disposto nos dois parágrafos iniciais do Artigo 32. Ou seja, se fosse preciso, os Estados que ratificassem a referida normativa deveriam punir os que se beneficiassem do labor infantojuvenil.

Várias instituições de caráter não governamental representando as mulheres Conselho Internacional de Mulheres, Conselho Internacional de Mulheres Judias, Federação Internacional de Mulheres de Carreira Jurídica e a Federação Internacional de Mulheres Juristas - participaram do debate sobre o labor infantojuvenil. Dentre estas organizações não governamentais, destaca-se a Federação Internacional de Mulheres de Carreira Jurídica que se manifestou a favor de punição para os que atentassem contra a saúde das crianças através de violência doméstica e uso de drogas. ${ }^{10}$

Não foi grande o número de países que se manifestou com ênfase no processo de redação da normativa internacional acerca do labor infantojuvenil: Nova Zelândia, Estados Unidos, Reino Unido, República Democrática Alemã, República Federal Alemã, Canadá, Filândia e Suriname, estiveram entre os mais destacados. De maneira geral, havia um consenso entre os legisladores dos referidos países e das organizações não governamentais sobre a perspectiva de regulamentar o labor infantojuvenil. Esta regulamentação, em grande medida, não fazia distinção entre os sexos dos infantes.

A "voz" dissonante neste debate era a da Organização Internacional do Trabalho. Os representantes da Organização Internacional do Trabalho em dois momentos das discussões insurgiram-se contra a utilização da Convenção Número 5, de 1921, no processo de definção da idade mínima para o ingresso dos infantes no mercado de trabalho. Esta Convenção, aprovada no início do século XX, preconizava 14 anos como a idade mínima a permitir o ingresso das pessoas de ambos os sexos nas atividades do setor industrial. Para os membros da referida entidade, deveria nortear o debate acerca do labor infantojuvenil o disposto na Convenção Número 138, aprovada em junho de 1973. ${ }^{11}$ Eis o que afirmavam os representantes da Organização Internacional do Trabalho:

\footnotetext{
${ }^{10}$ Office of the United Nations High Commissioner for Human Rights. Legislative History of the Convention on the Rights of the Child, Save the Children, 2007, p. 701.

${ }^{11}$ ORGANIZAÇÃO INTERNACIONAL DO TRABALHO. Convenção Número 138 sobre a idade mínima de admissão ao emprego, de 06 de junho de 1973.
} 
The Convention makes provision for the pursuit of a national policy aimed at the abolition of child labour and the progressive raising of the minimum age for admission to employment or work to a level consistent with the fullest physical and mental development of young persons. It establishes different age levels for admission to employment in general, for employment dangerous to health, safety or morals, and for light work under specified conditions, and introduces various other elements of flexibility in regulating these matters. (Office of the United Nations High Commissioner for Human Rights. Legislative History of the Convention on the Rights of the Child, Save the Children, 2007, p. 700, grifo nosso.) ${ }^{12}$

A Organização Internacional do Trabalho preconizava a abolição de trabalho infantojuvenil dos diferentes países a partir de políticas formuladas pelos Estados nacionais. Proposta possivelmente considerada radical por muitos membros dos corpos diplomáticos, uma vez que a mão de obra infantojuvenil, especialmente nos países em que a agricultura familiar era o "motor" da economia, era de fundamental importância. A referida entidade também não prescrevia uma idade mínima para o ingresso dos infantes no mercado de trabalho. Para os membros da Organização Interncional do Trabalho era o setor econômico - agricultura, comércio, indústria e serviços - com suas especificidades ou características que determinaria esta idade mínima "flexibilizada" entre 14 e 18 anos. Este processo também seria diferenciado para os países cuja economia e instituições educacionais ainda não estavam suficientemente "desenvolvidas" e para os países que em que este processo já havia ocorrido. Na redação final da normativa internacional, a proposta da Organização Internacional do Trabalho prevaleceu pelo menos em parte, uma vez que não foi estipulada a idade mínima de 14 anos.

A noção de infância burguesa tem como uma de suas premissas básicas a assertiva segundo a qual a criança é um ser em formação. Nesta perspectiva, a produção do corpo do infante de maneira saudável é vital, especialmente quando esta população necessita trabalhar. Os representantes da Organização das Nações Unidas para Alimentação e Agricultura — Food and Agriculture Organization of the United Nations (FAO) - , durante

\footnotetext{
${ }^{12}$ A Convenção (número 138) prevê a prossecução de uma política nacional para a abolição do trabalho infantil e o aumento progressivo da idade mínima para admissão a emprego ou trabalho a um nível compatível com o pleno desenvolvimento físico e mental dos jovens. Ela estabelece diferentes níveis de idade para admissão ao emprego, em geral, para o emprego perigoso para a saúde, segurança ou moral, e para os trabalhos leves sob condições específicas e introduz vários outros elementos de flexibilidade para regulamentar estas matérias.
} 
o debate acerca do labor infantojuvenil, apresentaram especial preocupação em relação à alimentação de meninos e meninas. Vale ressaltar que os representantes da entidade enunciaram que era preciso combater a discriminação existente em muitas sociedades em relação à deficiente alimentação fornecida às meninas. Para esta instituição, a alimentação da criança, do adolescente e do jovem consistia em um direito que deveria ser garantido a partir de políticas sociais de amplitude nacional. Verifique-se a seguir parte da proposição apresentada pelos representantes da FAO nos debates:

Three aspects should be considered in the definition of the child's right to food. The State Parties should:

(a) Recognize the children's right to food and the significance of food culture as part of a wider cultural identity (national obligation to respect the right to food).

(b) Prevent distortion of positive nutritional aspects of existing food patterns and develop national legislation and administrative mechanisms and procedures to protect and facilitate a valid food procurement for all children (national obligation to protect the right to food).

(c) Incorporate nutritional considerations into relevant development activities and formulate and execute policies, plans and programmes to facilitate and assist children in obtaining viable food procurement (national obligation to fulfil the right to food). (Office of the United Nations High Commissioner for Human Rights. Legislative History of the Convention on the Rights of the Child, Save the Children, 2007, p. 706. $)^{13}$

Por fim, chama atenção o fato de que os membros do Fundo das Nações Unidas para a Infância — United Nations Children's Fund (UNICEF) — manifestaram-se de forma muito tímida nas dicussões ocorridas ao longo da década sobre o labor infantojuvenil. Seus representantes ratificaram o proposto pela Organização Internacional do Trabalho em relação à Convenção Número 138 sendo que, para atingir estes objetivos, os estados

\footnotetext{
${ }^{13}$ Três aspectos devem ser considerados na definição dos direitos da criança ao alimento. Os Estados Partes devem:

(a) Reconhecer o direito da criança ao alimento, e ao significado da cultura alimentar como parte de uma cultura identitária maior (obrigação nacional de respeitar o direito à alimentação).

(b) Prevenir a distorção de possíveis aspectos nutricionais de padrões alimentares existentes e mecanismos administrativos com procedimentos para proteger e facilitar uma licitação alimentar válida para toda criança (obrigação nacional de proteger o direito à alimentação).

(c) Incorporar considerações nutricionais em atividades de desenvolvimento relevantes, formulando e executando políticas, planos e programas para facilitar e dar assistência a crianças na obtenção de licitações para alimentação viável (obrigação nacional de cumprir o direito à alimentação).
} 


\section{Ecos dos debates da Convenção sobre os Direitos da Criança na legislação brasileira}

Os "ecos" destes debates realizados no campo jurídico internacional chegavam até a sociedade brasileira por intermédio, principalmente, dos representantes da UNICEF que atuavam no Brasil junto às instituições para os "menores carentes" nas décadas de 1970 e 1980. Estes profissionais difundiam na mídia impressa um discurso sobre os problemas enfrentados pela infância pobre no país (OLIVEIRA, 2008). Este discurso era pautado, muitas vezes, em informações advindas de relatórios sociais realizados por organizações não governamentais estrangeiras afiliadas à ONU sobre temas da infância brasileira (BETHOUX, 2011). ${ }^{14}$

Desde o início do século XX, filhos e filhas das famílias pobres foram considerados um problema social no Brasil. Todavia, em alguns momentos históricos esta questão adquiriu maior vulto e novos contornos. A sociedade brasileira, na década de 1970, passava por um intenso processo de urbanização. Populações oriundas de cidades pequenas e da zona rural migravam para os centros urbanos de médio e grande porte em busca de melhores condições de vida, entendidas, sobretudo, como possibilidade de acesso a um trabalho, mobilidade social e consumo moderno. Segundo o Instituto Brasileiro de Geografia e Estatística, no início da década de 1980, o Brasil possuía 82.013.375 habitantes que viviam na zona urbana e 39.137 .198 na zona rural. ${ }^{15}$ O período do chamado "milagre econômico" e seus desdobramentos, calcado na modernização da infraestrutura do país e no desenvolvimento dos setores industrial e de serviços, foi marcado pela formação um grande exército de trabalhadores e trabalhadoras urbanos com baixa remuneração salarial. Parte da população que migrou para as cidades conseguiu galgar a sonhada ascensão social e atingiu rendas familiares de trabalhadores

\footnotetext{
${ }^{14}$ Ver, por exemplo: FÉDÉRATION INTERNATIONALE DES DROITS DE L'HOMME. Rapport de Mission. La prostitution des enfants au Brésil. Bibliothèque des Sciences Po - Paris.

${ }^{15}$ INSTITUTO BRASILEIRO DE GEOGRAFIA E ESTATíSTICA. Censo demográfico de 1980. População recenseada.
} 
formais, habitantes de subúrbios, com algumas garantias legais e acesso a determinados serviços públicos. Outra parcela desta população permaneceu ou tornou-se empobrecida e passou a habitar assentamentos urbanos precários e geralmente irregulares, em loteamentos localizados em periferias ou em morros, no que se conhece no Brasil como favelas.

A socialização das crianças, adolescentes e jovens por meio das relações de trabalho tornara-se, ao longo da trajetória histórica da sociedade brasileira, quase uma regra para meninas e meninos pobres no mundo rural e urbano. Nos anos de 1970, o quadro de ampla difusão das práticas de labor infantojuvenil mantinha-se praticamente inalterado nos centros urbanos, especialmente para as populações migrantes. Em função, sobretudo, dos baixos rendimentos auferidos pelas mães, pais e outros parentes em suas atividades profissionais, garotas e garotos eram obrigados a ingressar nos mercados de trabalho formal e informal. Paulatinamente, as atividades do mercado de trabalho informal, tais como o tráfico de drogas, a exploração sexual e a mendicância, passaram a ser exercidas por uma parcela maior de crianças e adolescentes pobres. Para os representantes do Estado brasileiro, esta situação, aos poucos, adquiria contornos cada vez mais graves. Em 1976, a Câmara dos Deputados instaurou a chamada Comissão Parlamentar de Inquérito do Menor que teve como resultado a elaboração de um documento, composto de 669 páginas, o qual subsidiou a ação dos representantes do Estado em relação à situação vigente, bem como na formulação da legislação para crianças e jovens implementada no período, o Código de Menores de $1979 .^{16}$

O Código de Menores de 1979 foi formulado tendo por base a doutrina jurídica da situação irregular. A ausência de práticas e valores relativos à norma familiar burguesa caracterizava a situação irregular no caso dos infantes considerados abandonados e infratores Diferente do Código de Menores de $1927,{ }^{17}$ esta nova legislação não tipificava os casos em que as autoridades judiciárias brasileiras poderiam retirar e/ou suspender 0 instituto jurídico da guarda de mães, pais ou outros parentes (AREND;DAMINELLI, 2014). Sendo assim, no período, uma quantidade significativa de crianças, adolescentes e jovens

\footnotetext{
${ }^{16}$ BRASIL. Lei número 6.697, de 10 de outubro de 1979.

${ }^{17}$ BRASIL. Decreto número 17. 943-A, de 12 de outubro de 1927.
} 
foi enviada para os abrigos tendo por justificativa somente a condição de pobreza de sua família. Por outro lado, famílias pobres que visavam à sobrevivência de sua prole, solicitavam aos juízes de menores uma vaga para os seus filhos e filhas nos abrigos.

O Código de Menores de 1979 abordava o tema do labor infantojuvenil somente em um artigo do Título VIII, intitulado “Do trabalho do Menor”. O Artigo 83 da referida lei afirmava o seguinte: “A proteção ao trabalho do menor é regulada por legislação especial”, ou seja, pela Consolidação das Leis do Trabalho (Artigos 402 a 441) sancionada em 1943, pelo Presidente Getúlio Vargas. Para os governantes daquele período, o fato de um contingente populacional ingressar no mercado de trabalho formal e informal desde a infância não constituía uma questão que devesse ser tratada no âmbito da legislação para o "menor".

Em 1964, no mesmo ano do golpe que impôs a ditadura militar, os novos governantes da nação instituíram a Fundação Nacional do Bem-Estar do Menor (FUNABEM), responsável pelas políticas sociais implantadas no país por aproximadamente 15 anos, especialmente, para a infância considerada infratora. Os pressupostos da Doutrina da Segurança Nacional, formulados na Escola Superior de Guerra, aliados à máxima da prevenção social, nortearam as ações do poder público (BASÍLIO, 1985). Grandes centros para a reclusão e a reabilitação, sobretudo de pessoas do sexo masculino acusadas de cometer infrações, foram criados nos diversos Estados da federação. Estas instituições de contenção social eram geridas por uma "sucursal" regional da FUNABEM instalada em cada Estado. Paulatinamente, denúncias sobre as violências infligidas aos adolescentes e jovens nestes estabelecimentos começaram a vir à tona por meio da imprensa e de entidades civis, como a Ordem dos Advogados do Brasil $(O A B)$. Nas décadas seguintes, as instituições de reclusão de adolescentes e jovens tornaram-se sinônimo de violação dos direitos humanos no país (VOGEL, 2001); (FRONTANA, 1999).

Este cenário de "cores sombrias" relativo à infância brasileira percebida como infratora e abandonada, começou a ser questionado no início dos anos de 1980. Um conjunto de vozes, na maioria das vezes em tom de denúncia, passou a manifestar-se em relação ao que se passava com crianças, adolescentes e jovens. Para Marcos Napolitano, 
Uma parcela significativa dos debates enunciados, sobretudo pela imprensa, acerca do "problema" da infância brasileira, tinha no seu horizonte a introdução da noção jurídica de sujeito de direitos, pautada no ideário dos Direitos Humanos. Esta noção jurídica, considerada revolucionária por muitos, deslocava o foco de atenção da sociedade civil e do Estado que, desde a primeira legislação para a infância formulada pelos republicanos brasileiros em 1927, caracterizava-se por ser “adultocêntrica”. Colocar em primeiro plano os interesses das crianças, adolescentes e jovens significava então questionar relações de poder instituídas há longa data entre os universos adulto e infantojuvenil, "corporificadas" nas legislações civis, penais e para a infância (SANDRINI, 2009).

Em 1990, o Estado brasileiro sancionou o Estatuto da Criança e do Adolescente em nível federal. Esta legislação foi instituída somente um ano depois da Convenção dos Direitos da Criança ter sido aprovada pela Organização das Nações Unidas. Entende-se que uma parcela significativa dos debates ocorridos durante aos anos de 1978 e 1989 foi incorporada na legislação brasileira. O Título II do Estatuto da Criança e do Adolescente, ao abordar os denominados “Direitos Fundamentais", refere-se à vida e à saúde; à liberdade, ao respeito e à dignidade; à convivência familiar e comunitária; à educação, à cultura, ao esporte e ao lazer; e à profissionalização e à proteção no trabalho.

O Capítulo V, intitulado “Do Direito à profissionalização e à proteção no trabalho”, procura regulamentar o labor infantojuvenil na ótica dos direitos, conjuntamente com a legislação trabalhista vigente no Brasil desde a década de 1940, referida anteriormente. ${ }^{18}$ Os temas presentes no Artigo 32, da Convenção dos Direitos da Criança, tais como a delimitação da faixa etária para o ingresso no mercado de trabalho (14 anos) e a interdição de horários e locais para a realização das atividades laborais, estão presentes no Estatuto da Criança e do Adolescente nos Artigos 60 e 67 conforme demonstra-se a seguir:

\footnotetext{
${ }^{18}$ BRASIL. Lei número 8.069, de 13 de julho de 1990. Capítulo V, Art. 60 - Art. 69.
} 
Art. 60 - É proibido qualquer trabalho a menores de quatorze anos de idade, salvo na condição de aprendiz.

Art. 67 - Ao adolescente empregado, aprendiz, em regime familiar de trabalho, aluno de escola técnica, assistido em entidade governamental ou não governamental, é vedado trabalho:

I - noturno, realizado entre as vinte e duas horas de um dia e as cinco horas do dia seguinte;

II - perigoso, insalubre ou penoso;

III - realizado em locais prejudiciais a sua formação e ao seu desevolvimento físico, psíquico, moral e social;

IV - realizado em horários e locais que não permitam a frequência à escola. ${ }^{19}$

Para finalizar, a História "oficial” do Estatuto da Criança e do Adolescente afirma que esta lei é fruto, sobretudo, dos debates ocorridos entre os Operadores do Direito brasileiros durante o período da redemocratização. Esta investigação procura demonstrar que os discursos dos Organismos Internacionais foram também de fundamental importância para que a "letra" da lei encontrasse determinada configuração. Esta imbricação entre os discursos em nível local/nacional e internacional talvez expliquem, em parte, porque a aplicação desta lei para a população infantojuvenil brasileira gerou e ainda gera tantas resistências por parte de diversos segmentos sociais.

\section{Referências}

AGAMBEN, Giorgio. Homo Sacer. O poder soberano e a vida nua. Belo Horizonte: Editora da UFMG, 2004, vol I.

ALANEN, Leena. Estudos feministas/estudos da infância: paralelos, ligações e perspectivas. In: CASTRO, Lucia Rabello de (Org.) Crianças e jovens na construção da cultura. Rio de Janeiro: Nau Editora, 2001, p. 69 - 92.

AREND, Silvia Maria Fávero; DAMINELLI, Camila Serafim. Políticas sociais para infância e juventude carente e infratora (1970-1980). In: BRANCHER, Ana Lice; LOHN, Reinaldo Lindolfo (Org.). Histórias na ditadura: Santa Catarina (1964-1985). Florianópolis: Editora UFSC, 2014, p. 181-205.

\footnotetext{
${ }^{19}$ BRASIL. Lei número 8.069, de 13 de julho de 1990. Capítulo V, Art. 60 - Art. 67.
} 
ARIÈS, Philippe. História social da criança e da família. Rio de Janeiro: LTC, 1981.

BASÍLIO, Luiz Cavalieri. O menor e a ideologia de segurança nacional. Belo Horizonte: Veja-Novo Espaço, 1985.

BETHOUX, Camille. La promotion des normes internationales des droits humains: le rôle de la Fédération Internationale des Droits de l'Homme (FIDH). Paris: Edition des Archives Contemporaines, 2011.

BOURDIEU, Pierre. A força do Direito. Elementos para uma sociologia do campo jurídico. In: . O Poder Simbólico. Rio de Janeiro: Bertrand, 1989.

CARVALHO, José Murilo. Cidadania no Brasil: o longo caminho. Rio de Janeiro: Civilização Brasileira, 2001.

COSSE, Isabella; LLOBET, Valeria; VILLALTA, Carla; ZAPIOLA, Maria Carolina (Comp.) Infancia: políticas y saberes en Argentina y Brasil. Buenos Aires: Teseo, 2011.

FRONTANA, Isabel. Crianças e adolescentes nas ruas de São Paulo. São Paulo: Edições Loyola, 1999.

FOUCAULT. Michel. História da sexualidade: a vontade de saber. Rio de Janeiro: Graal, 2007, vol. 1.

GREGORI, Maria Filomena. Viração: experiências de meninos nas ruas. São Paulo: Companhia das Letras, 2000.

LOUREIRO, José. A infância dos mortos (Pixote). São Paulo: Abril Cultural, 1984.

LIEBEL, Manfred. Enfants, droits et citoyenneté : faire émerger la perspective des enfants sur leurs droits. Paris: L'Harmattan, 2010.

MARSHALL, Thomas Humprey. Cidadania, classe social e status. Rio de Janeiro: Zahar, 1967.

MONACO, Gustavo Ferraz de Campos. A proteção da criança no cenário internacional. Belo Horizonte: Livraria Del Rey Editora, 2005.

NAPOLITANO, Marcos. Cultura e poder no Brasil contemporâneo. Curitiba: Juruá, 2002.

OLIVEIRA, Fabiana de. A criança e a infância nos documentos da ONU: a produção da criança como 'portadora de direitos' e a infância como 'capital humano do futuro. 2008. Tese (Doutorado em Educação) - Universidade Federal de São Carlos, São Carlos, 2008.

OESTREICH, Joel E. UNICEF and the implementation of the Convention on the Rights of the Child. Global Governance, n. 4, p. 183-198, 1998. 
PASSETTI, Edson. Crianças carentes e políticas públicas. In: DEL PRIORE, Mary. História das crianças no Brasil. São Paulo: Contexto, 2004, p. 347-375.

PINHEIRO, Ângela. Criança e adolescente no Brasil: porque o abismo entre a lei e a realidade. Fortaleza: Editora da UFC, 2006.

PIOVESAN, Flávia. Direitos humanos e o direito constitucional internacional. São Paulo: Saraiva, 2013.

RIZINNI, Irene. Crianças e menores: do pátrio poder ao pátrio dever. Um histórico da legislação para a infância no Brasil. In: PILOTTI, Francisco; RIZINNI, Irene (Orgs.). A arte de governar crianças: a história das políticas sociais, da legislação e da assistência à infância no Brasil. São Paulo: Cortez, 2011, p. 97-149.

SANDRINI, Paulo Roberto. 0 controle social da adolescência brasileira: gênese e sentidos do Estatuto da Criança e do Adolescente. 2009, ooof. Tese (Doutorado em Ciências Humanas) - Universidade Federal de Santa Catarina, Florianópolis, 2009.

STEPAN, Alfred (Org.) Democratizando o Brasil. Rio de Janeiro: Paz e Terra, 1988.

VASSEUR, Paul. Protection de l'enfance et cohésion sociale du IVe au XXe siècle. Paris: L'Harmattan, 1999.

VOGEL, Arno. Do Estado ao Estatuto; Propostas e vicissitudes da política de atendimento à infância e adolescência no Brasil contemporâneo. In: PILOTTI, Francisco; RIZZINI, Irene (Orgs.). A arte de governar crianças: a história das políticas sociais, da legislação e da assistência à infância no Brasil. São Paulo: Cortez, 2001, p. 287-221. 
Recebido em 28/02/2015 Aprovado em 29/03/2015

Universidade do Estado de Santa Catarina - UDESC Programa de Pós-Graduação em História - PPGH Revista Tempo e Argumento Volume 07 - Número 14 - Ano 2015 tempoeargumento@gmail.com 